\title{
THE EFFECT OF DRYING AND STORAGE CONDITIONS ON CASE HARDENING OF SCOTS PINE AND NORWAY SPRUCE TIMBER
}

\author{
V. Tarvainen ${ }^{1}$, A. Ranta-Maunus ${ }^{1}$, A. Hanhijärvi' ${ }^{1}$ H. Forsén ${ }^{1}$
}

\begin{abstract}
Case hardening is a feature of dried wood that causes the wood to deform (cup) after re-sawing and equalising the moisture content. VTT has analysed case hardening with the aid of the simulation model PEO and with experimental drying, conditioning and storage tests. Case hardening cannot be predicted by the moisture content gradient alone. However, the case hardening gap after drying to a high final moisture content of $18 \%$ is nearly identical to the calculated gap caused by cupping when the moisture gradients of the two halves of the test piece are equalised.

24 hours (proposed in ENV 14464) is too little time to show the total cupping when keeping the sliced specimens in a plastic bag. Thus the test according the standard doesn't show the whole cupping tendency of, for example, panels when the moisture content is equalised after re-sawing the timber and planing the billets.

Increasing the kiln drying rate increases the resulting case hardening tendency. With effective conditioning at the drying temperature, or with steaming after cooling, it is possible to reduce or remove the case hardening. But at normal temperatures in end-use or storage of timber the case hardening diminishes very slowly, despite the equalising of the moisture content in the cross-section.
\end{abstract}

Keywords: case hardening, cupping, drying, conditioning, re-sawing, simulation, Scots Pine, Norway spruce

\section{INTRODUCTION}

Case hardening is a term that is often used to describe the quality of dried wood. The term itself does not unambiguously say what it means. Therefore, a survey has been conducted among internationally renowned experts. The following questions were asked:

- How do you define case hardening?

- What are the disadvantages of case hardening for the end users?

- Do you have measured results to describe the phenomenon of case hardening?

A common feature of the answers is that case hardening is regarded as being related to drying stresses and that it causes deformations after the original dried cross-section has been re-sawn or otherwise machined. The harm is caused by the deformed surface of the final product, by the wasted material when working the re-sawn surface back to a planed form or by the problems with working the wood because of the immediate deformation of the cross-section during planing or sawing.

It was also stated that case hardening is caused by the mechano-sorptive creep deformation during the early part of drying when the surface is under tensile stress. This strain is not recoverable under dry service conditions but can be counteracted by conditioning the wood at the drying temperature: the compressive stress causes compressive creep strain, making the total elongation of the outer surface smaller.

${ }^{1}$ VTT - Technical Research Centre of Finland. P.O.Box 1000. FIN-02044 VTT, Finland.

Corresponding author: veikko.varvainen@vtt.fi

Received: December 14, 2005. Accepted: March 7, 2006. 
The term case hardening is often used more loosely, including meanings other than those described above. On the other hand, the term case hardening does not describe the phenomenon. Therefore, it would be better to use distinct well-defined terms for different phenomena, such as:

- residual stress, meaning the physical state of stress after drying, causing deformation immediately the wood is re-sawn or planed.

- stretched surface, elongated surface layer during drying resulting in cupping when re-sawn and equalised. - dry shell, dry and nutrition-filled cells on the surface, which can slow down the drying process and may explain the origin of the term case hardening. Hardening may also refer to the hardness of the surface because it is dry.

Based on this survey, a definition for case hardening can be suggested: Case hardening is a feature of dried wood that causes it to deform into a cup shape after re-sawing and equalising the moisture content (Ranta-Maunus et al. 2001).

The CEN standard ENV 14464:2002 Sawn timber - Method for assessment of case-hardening gives a method that can be used to measure the tendency for cupping when the product is manufactured by resawing dried sawn timber. This method is illustrated in Appendix 1, Figures 1 - 4.

The objective of this research is to experimentally study case hardening as defined above, to verify how well our wood drying simulation software can predict case hardening, and to find ways of minimising case hardening.

\section{MATERIALS AND METHODS}

Case hardening measurements were performed on Scots Pine and Norway spruce timber after different drying methods, and also after 1 and 6 months storage in different climates. The material used for the simulations was $50 \times 150 \mathrm{~mm}$ Scots pine heartwood timber.

\section{CALCULATION OF CASE HARDENING}

The numerical analysis of the case hardening tendency has been made with the use of a twodimensional Finite Element Program called PEO developed by VTT. This calculates the moisture changes and development of stresses during drying. After cooling, the central line element connections are released and cupping of the two pieces is calculated during equalisation of the moisture.

The calculation of the moisture changes in the cross-section is made using a two-dimensional isotropic model for the moisture transfer in the transverse (RT) plane of the wood. The model uses a reduced approach that considers all the different flow components with a single, diffusion-type differential equation. This simplified model uses the diffusion coefficient and the surface emission coefficient as effective model parameters, which take the variations in the flow properties into consideration and whose values are obtained through a comprehensive empirical fit to the experimental data. The model is introduced in more detail in Hukka (1996), Ranta-Maunus (1994), Hanhijärvi and Mackenzie-Helnwein (2003), and Mackenzie-Helnwein and Hanhijärvi (2003).

The spatial discretization is done by the control volume method when calculating the moisture transfer and by finite element method when calculating the mechanical response using a rectangular calculation mesh (Figure 1). 


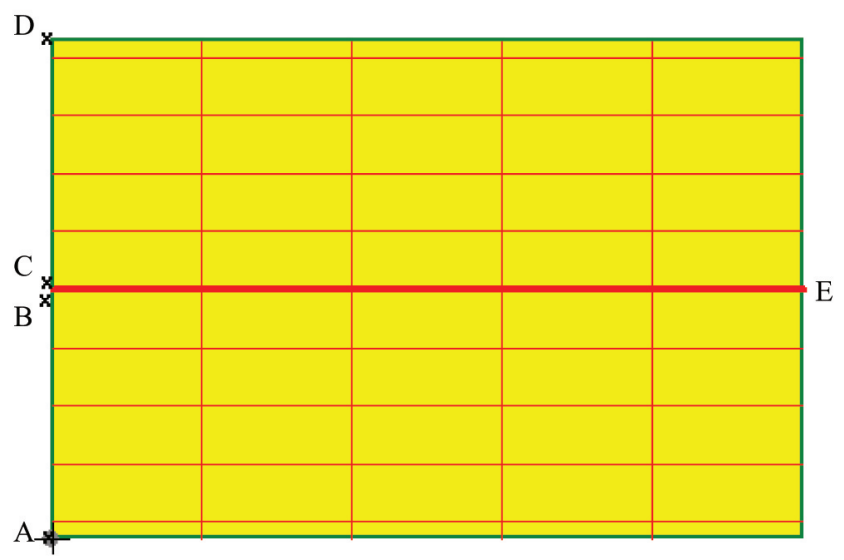

Figure 1. An example of the mesh used in the drying simulations with the PEO program, crosssection size $50 \times 150 \mathrm{~mm}$. The figure only shows the right half of the specimen, with the vertical axis of symmetry at the left border of the mesh. The pith of the stud is at point A. Points A-D refer to the results shown in Fig. 3. The vertical position of point $\mathrm{E}$ is fixed.

\section{Effect of drying schedule}

The material used for the simulations was $50 \times 150 \mathrm{~mm}$ Scots pine heartwood timber. The pith was on inside face of the studs. The calculation mesh used is presented in Figure 1.

Drying schedules were selected with the following criterion:

- Only minor checking is allowed

- Wet bulb depression is in a fast schedule higher than in a slow schedule

Initially, the fast and slow schedules were the same to avoid checking. In the fast schedules the end phase was speeded up by increasing the wet bulb depression more than in the slow schedules.

Schedules containing additional equalizing phase to reduce moisture content variation and to some extent moisture content gradient were also simulated. In these, the basic schedule was shortened so that after the equalizing phase the average end moisture content was same as after drying without equalizing. The target moisture contents were 18 and $8 \%$. The drying schedules are specified in Table 1.

Table 1. Drying schedules used in PEO simulations and moisture content gradient after drying, $\mathrm{MC}_{\text {grad }}$. The schedules are specified with target moisture content $\mathrm{MC}_{\text {target }}$, drying temperature $\mathrm{T}_{\text {drying }}$, maximum wet bulb depression $\mathrm{WBD}_{\max }$, and duration of drying $\left(\mathrm{t}_{\text {drying }}\right)$ and equalizing $\left(\mathrm{t}_{\text {equal.. }}\right)$.

\begin{tabular}{|r|c|c|c|c|c|c|c|}
\hline Drying schedule & $\begin{array}{c}\mathrm{MC}_{\text {target }} \\
\%\end{array}$ & $\begin{array}{c}\mathrm{T}_{\text {drying }} \\
{ }^{\circ} \mathrm{C}\end{array}$ & $\begin{array}{c}\mathrm{WBD}_{\text {max }} \\
{ }^{\circ} \mathrm{C}\end{array}$ & $\begin{array}{c}\mathrm{t}_{\text {drying }} \\
\mathrm{h}\end{array}$ & $\begin{array}{c}\mathrm{t}_{\text {equal. }} \\
\mathrm{h}\end{array}$ & $\begin{array}{c}\mathrm{t}_{\text {tot }} \\
\mathrm{h}\end{array}$ & $\begin{array}{c}\mathrm{MC}_{\text {gradient }} \\
\% \text {-unit }\end{array}$ \\
\hline 18fast60 & 18 & 60 & 14 & 117 & & 117 & 5,7 \\
\hline 18fast60equal & 18 & 60 & 14 & 107 & 33 & 140 & 3 \\
\hline 18slow60 & 18 & 60 & 7 & 157 & & 157 & 3,9 \\
\hline 18slow60equal & 18 & 60 & 7 & 122 & 66 & 188 & 2,1 \\
\hline 18fast80 & 18 & 80 & 14 & 78 & & 78 & 6,5 \\
\hline 18fast80equal & 18 & 80 & 14 & 72 & 17 & 89 & 3,8 \\
\hline 18slow80 & 18 & 80 & 7 & 96 & & 96 & 4,6 \\
\hline 18slow80equal & 18 & 80 & 7 & 66 & 54 & 120 & 2,2 \\
\hline 8fast60 & 8 & 60 & 22 & 256 & & 256 & 1,8 \\
\hline 8sast60equal & 8 & 60 & 22 & 240 & 65 & 305 & 0,7 \\
\hline 8slow60 & 8 & 60 & 18 & 309 & & 309 & 1,4 \\
\hline 8fastoqual & 8 & 60 & 18 & 292 & 69 & 361 & 0,5 \\
\hline 8faequal & 8 & 80 & 25 & 150 & & 150 & 2,1 \\
\hline 8slow80 & 8 & 80 & 25 & 142 & 38 & 180 & 0,7 \\
\hline
\end{tabular}


An example of drying curve and tangential stress (relative) development on the surface of the outside face during the drying schedule 18fast60equal is illustrated in Fig. 2.

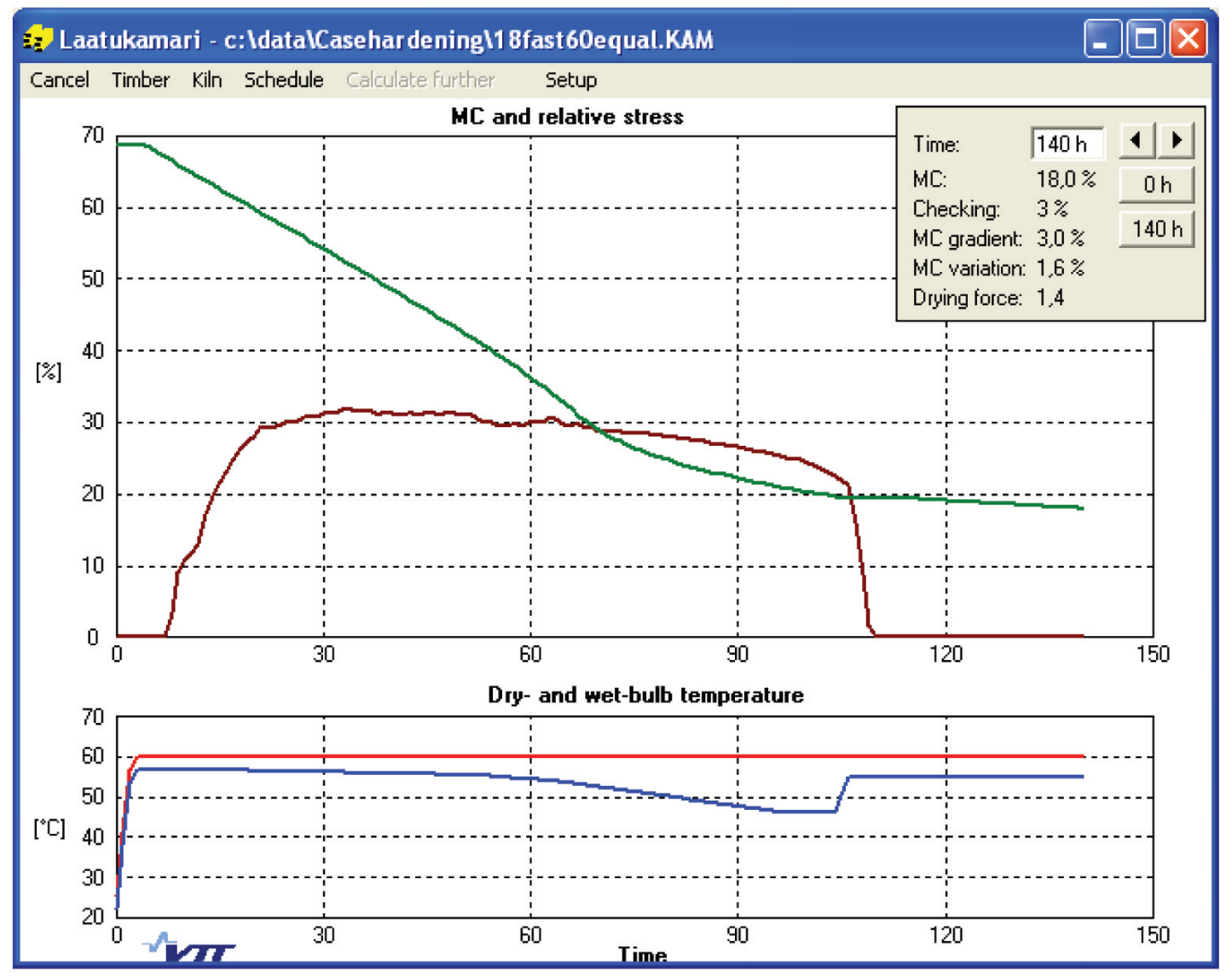

Figure 2. Drying schedule 18fast60equal. Moisture content and drying stress curves in the upper part, dry and wet bulb temperatures in the lower part.

\section{Effect of timber dimension and sawing pattern}

The following Scots Pine dimensions were analysed: width $150 \mathrm{~mm}$ and thicknesses 25, 32, 50 and $75 \mathrm{~mm}$. The target moisture content was $18 \%$. The basic density was $450 \mathrm{~kg} / \mathrm{m}^{3}$. The initial MC varies in real life according the sawing pattern. Despite that, only the heartwood properties and an initial MC of $35 \%$ were used in the PEO analysis.

Different parts of the log were analysed in the PEO calculations, so the logs were sawn with 2, 3 and 4 ex $\log$ (number of central yield pieces); fictional ex $\log 200$ was also used to analyse the situation where the annual rings were parallel to the timber faces.

\section{Effect of conditioning on CEN-gap}

The effect of different conditionings after drying on case hardening was also analysed. Table 2 presents the drying schedule and Table 7 shows the different additional conditioning phases and calculated CEN-gap. 
Table 2. The drying schedule before conditioning. End MC is $18 \%$.

\begin{tabular}{|c|c|c|}
\hline $\begin{array}{c}\text { Time } \\
\mathrm{h}\end{array}$ & $\begin{array}{c}\mathrm{Td} \\
{ }^{\circ} \mathrm{C}\end{array}$ & $\begin{array}{c}\mathrm{Tw} \\
{ }^{\circ} \mathrm{C}\end{array}$ \\
\hline 0 & 10 & 7 \\
\hline 3 & 60 & 57 \\
\hline 50 & 60 & 55 \\
\hline 90 & 60 & 46 \\
\hline 112 & 60 & 46 \\
\hline
\end{tabular}

\section{The effect of storage time}

In analysing the effect of storage time on case hardening with the PEO simulation model it was assumed that the timber was held in $20^{\circ} \mathrm{C}$ and $52 \% \mathrm{RH}$ for one, two and six months in a room with no air movement before the CEN test.

\section{MEASUREMENT OF CASE HARDENING}

\section{Effect of the equalising time after slicing}

CEN-test specimens were prepared from 20 spruce battens $(32 \times 125 \mathrm{~mm})$ dried in a progressive kiln. One specimen from each batten was kept in a plastic bag after the slicing and one parallel specimen in a room atmosphere. Case hardening was measured every 24 hours for one week and at 10 and 20 days after slicing.

\section{Effect of drying schedule, storage conditions and equalizing time after slicing}

For the experimental case hardening tests both Norway spruce and Scots Pine timber was selected from industrial production. The nominal timber thickness was $50 \mathrm{~mm}$ and the width in most cases was $100 \mathrm{~mm}$. The dryings were selected so that there were fast and slow schedules with and without conditioning. In some cases the industrially dried timber was steam conditioned in VTT's laboratory kiln. For comparison, two charges of Spruce timber were HT-dried at VTT. One charge was dried with and the other without steam conditioning.

The moisture content and density were measured after drying (and conditioning). The CEN gap was measured according the standard 24 hours after the slicing and storage in a plastic bag. The gap was also measured one week and one month after the slicing in order to obtain the total deformations in the slices.

The timber was cut into $60 \mathrm{~cm}$-long sections for studying the effect of storage. These were conditioned in different climates, as shown in Table 3.

Table 3. Conditioning climate and duration for timber before case hardening test

\begin{tabular}{|l|c|c|}
\hline Climate & 1 Month & 6 Months \\
\hline $20^{\circ} \mathrm{C} / 65 \% \mathrm{RH}$ & $\mathrm{x}$ & $\mathrm{x}$ \\
\hline $20^{\circ} \mathrm{C} / 35 \% \mathrm{RH}$ & $\mathrm{x}$ & $\mathrm{x}$ \\
\hline Outdoors & $\mathrm{x}$ & $\mathrm{x}$ \\
\hline
\end{tabular}




\section{RESULTS AND DISCUSSION}

\section{CALCULATED CASE HARDENING}

An example of the results of the PEO simulation is presented in Figures $3 a-3 d$. Figure $3 c$ presents the displacements of points in the middle of the surfaces and just beneath and over the centreline (slicing line, Fig. 1). In the drying and conditioning phase the displacements are due to cupping of the crosssection as one piece. After slicing, the upper and lower parts of the specimen cup in opposite directions when the moisture is equalised. The calculation indicates that the moisture content gradient disappears in one week when conditioning in a plastic bag. The calculated time needed for moisture equalization of the test specimen inside a plastic bag may be inaccurate and has not been verified by tests.
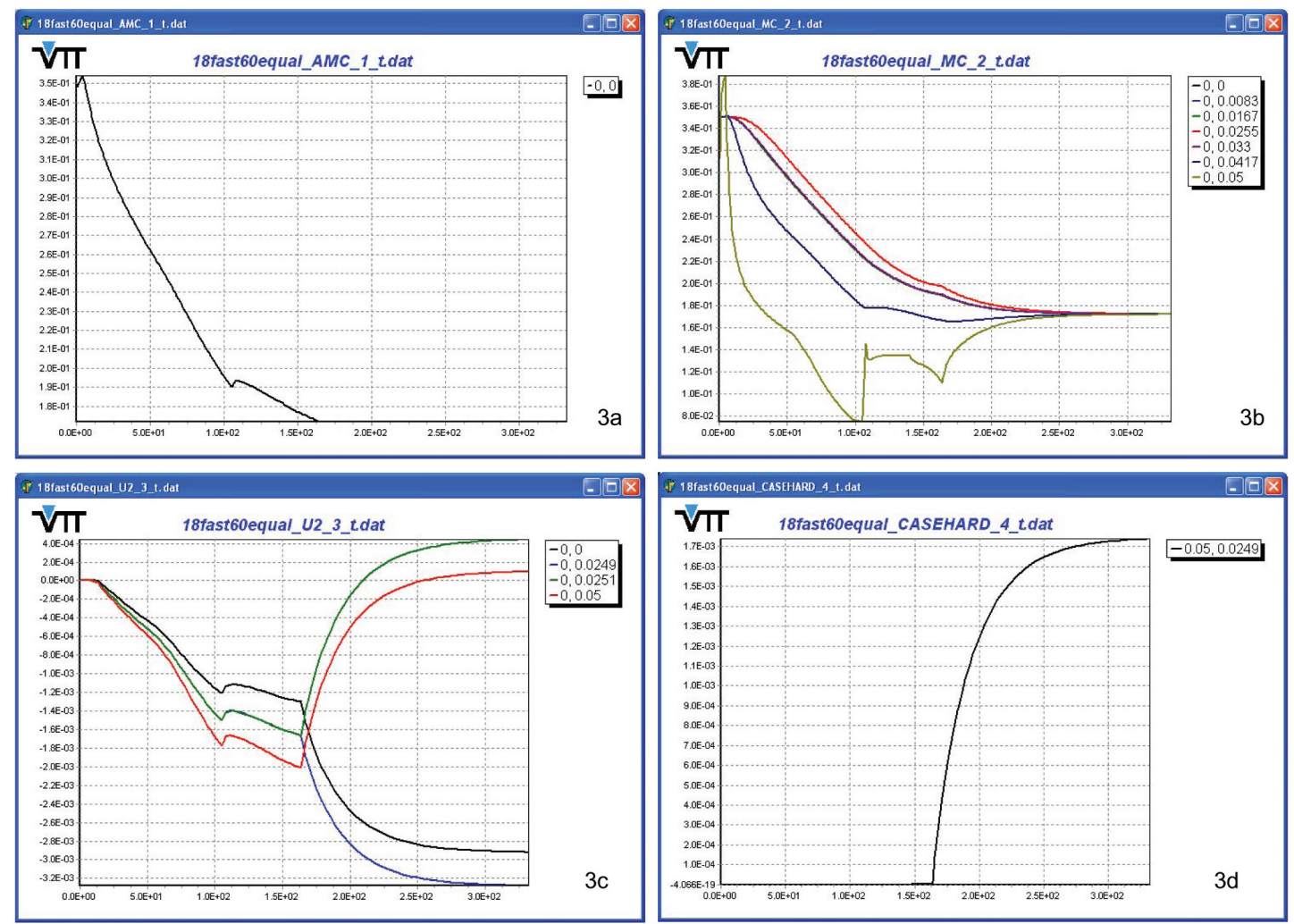

Figure 3. Various calculated variables as function of time $[\mathrm{h}]$ (horizontal axis).

Vertical axis: (a) Average moisture content [-]; (b) moisture content on the surfaces and inside the board [-]; (c) vertical displacements of the points A-D [m] , (see Fig. 1) and (d) case hardening opening in the drying phase and after slicing the test specimen [m]. Drying schedule as in Table 1,

18 fast60equal.

\section{Effect of drying schedule}

The results of the PEO simulations are presented in Table 4. In order to study whether the case hardening gap can be predicted simply by moisture gradient alone, simulated case hardening gap values are compared with the calculated values of the cupping caused only by equalisation of the moisture distribution at the moment of splitting (i.e. freezing creep and elastic deformations to be permanent at the moment of splitting). 
Table 4. Simulated CEN gap and gap due to equalising the MC gradient without prior creep history.

\begin{tabular}{|r|c|c|}
\hline Drying schedule & $\begin{array}{c}\text { CEN-gap } \\
\mathrm{mm}\end{array}$ & $\begin{array}{c}\text { Gap due MC- } \\
\text { gradient, } \mathrm{mm}\end{array}$ \\
\hline 18fast60 & 2,5 & 2,5 \\
\hline 18fast60equal & 1,8 & 1,7 \\
\hline 18slow60 & 1,8 & 1,8 \\
\hline 18slow60equal & 1,3 & 0,7 \\
\hline 18fast80 & 2,5 & 2,4 \\
\hline 18fast80equal & 1,7 & 1,7 \\
\hline 18slow80 & 1,9 & 1,9 \\
\hline 18slow80equal & 1,2 & 1,4 \\
\hline 8fast60 & 2,1 & 1,4 \\
\hline 8fast60equal & 1,7 & 0,8 \\
\hline 8slow60 & 1,8 & 1,1 \\
\hline 8slow60equal & 1,4 & 0,7 \\
\hline 8fast80 & 2,1 & 1,5 \\
\hline 8fast80equal & 1,7 & 1,5 \\
\hline 8slow80 & 1,7 & 1,1 \\
\hline 8slow80equal & 1,4 & 0,8 \\
\hline
\end{tabular}

As expected, the calculated gaps are largest after fast drying without equalizing, smaller when equalized and about equal after slow drying and after fast drying with equalizing. When drying to $18 \%$ without equalizing, the case hardening gap is nearly the same as the gap caused by equalizing the moisture content. After equalizing, the gap is smaller but not much different from the pure moisture gradient effect.

When dried to an $8 \%$ final MC, the simulated CEN case hardening gaps are about $50 \%$ larger than cupping due to the moisture gradient only, when equalizing is not part of the drying. The CEN gap is twice the cupping caused by moisture gradient only in case of schedules with equalizing.

These simulated data show that the case hardening test results and $\mathrm{MC}$ gradients are correlated, but are obviously two different measurements that cannot replace each other.

\section{Effect of timber dimension and sawing pattern}

The calculated values of the case hardening gap are presented in Table 5.

Table 5. Effect of sawing pattern and dimension on case hardening gap ( $\mathrm{mm} / 100 \mathrm{~mm})$. Width is 150 $\mathrm{mm} . \mathrm{Ex} \log =$ number of battens in central yield.

\begin{tabular}{|c|c|c|c|c|c|}
\hline $\begin{array}{c}\mathrm{D} \\
\mathrm{mm}\end{array}$ & $\begin{array}{c}3 \text { ex log } \\
\text { inner }\end{array}$ & $\begin{array}{c}2 \text { ex log } \\
\text { outer }\end{array}$ & $\begin{array}{c}3 \text { ex log } \\
\text { outer }\end{array}$ & $\begin{array}{c}4 \text { ex log } \\
\text { outer }\end{array}$ & $\begin{array}{c}200 \text { ex log } \\
\text { outer }\end{array}$ \\
\hline 25 & & & & 5,5 & \\
\hline 32 & 2,3 & 3,7 & 4,3 & 4,6 & 4,8 \\
\hline 50 & 1,3 & 2,5 & 2,9 & 3,1 & 3,3 \\
\hline 75 & 0,8 & 1,5 & 1,8 & 1,9 & 1,9 \\
\hline
\end{tabular}


The gap does decrease with increasing thickness, partly due to the milder drying schedules for thicker dimensions and partly due to the higher stiffness of the cross-section halves.

Pith boxed pieces ( 3 ex log inner) cup less after slicing. The cupping does increase with increasing the distance from the pith.

Table 6 presents the effect of the sawing setup on the cupping of the two halves from $32 \times 150 \mathrm{~mm}$ timber and also the sum of them (CEN gap) after slicing.

Table 6. The effect of sawing pattern on cupping $(\mathrm{mm} / 100 \mathrm{~mm})$ of the halves and the CEN gap.

Timber dimension $32 \times 100 \mathrm{~mm}$.

\begin{tabular}{|l|c|c|c|}
\hline batten & outer side & pith side & CEN gap \\
\hline 3 ex log pith boxed & 1,1 & 1,1 & 2,3 \\
\hline 3 ex log outer pcs & 3,0 & 1,5 & 4,4 \\
\hline 4 ex log inner pcs & 2,9 & 0,7 & 3,7 \\
\hline 4 ex log outer pcs & 2,8 & 1,8 & 4,6 \\
\hline 200 ex log & 2,4 & 2,4 & 4,7 \\
\hline
\end{tabular}

The halves from the pith boxed battens and very far from the pith sawn battens do cup symmetrically. Near the pith the inner slice cups much more than the outer one. The symmetry increases with distance from the pith.

\section{Effect of conditioning on CEN gap}

Table 7 shows the different conditioning phases after drying with the schedule presented in Table 2 and simulated CEN gap values.

Table 7. The calculated CEN gap after different conditioning phases. Scots Pine 50 x $150 \mathrm{~mm}, 2$ ex $\log$. The drying schedule is in Table 2 .

\begin{tabular}{|c|c|c|}
\hline \multicolumn{2}{|c|}{ Conditioning at $60^{\circ} \mathrm{C}$} & \multirow{2}{*}{$\begin{array}{c}\text { CEN gap } \\
\mathrm{mm}\end{array}$} \\
\hline $\mathrm{Tw}-\mathrm{Td}{ }^{\circ} \mathrm{C}$ & Time $\mathrm{h}$ & 2,6 \\
\hline & 0 & 2,1 \\
\hline 4 & 6 & 1,9 \\
\hline 4 & 12 & 1,7 \\
\hline 4 & 24 & 1,5 \\
\hline 3 & 24 & 1,2 \\
\hline 2 & 24 & \\
\hline
\end{tabular}

As expected, the CEN gap decreases with increasing conditioning time and air humidity.

\section{The effect of storage time on case hardening}

Table 8 presents the effect of storage time before CEN test on moisture content and case hardening. 
Table 8. The calculated effect of storage time on the CEN gap. Scots Pine timber (50 x $150 \mathrm{~mm})$. Storage climate: $20 / 14^{\circ} \mathrm{C}(52 \% \mathrm{RH})$.

\begin{tabular}{|c|c|c|}
\hline $\begin{array}{c}\text { Storage time } \\
\text { months }\end{array}$ & $\begin{array}{c}\text { MC } \\
\%\end{array}$ & $\begin{array}{c}\text { CEN gap } \\
\mathrm{mm}\end{array}$ \\
\hline 0 & 12,0 & 2,3 \\
\hline 1 & 9,5 & 1,7 \\
\hline 2 & 9,0 & 1,5 \\
\hline 6 & 8,7 & 0,8 \\
\hline
\end{tabular}

The longest storage period reduced the case hardening remarkably. But, compared with the conditioning time, which is needed in the kiln for achieving the same result, the low temperature storage is very time consuming.

\section{EXPERIMENTAL RESULTS}

\section{Effect of the equalising time after slicing}

The result in Figure 4 shows that the equalisation in plastic bags is slower than in an open space. However it should be noticed that the total cupping in room conditions is higher due to the lower EMC.

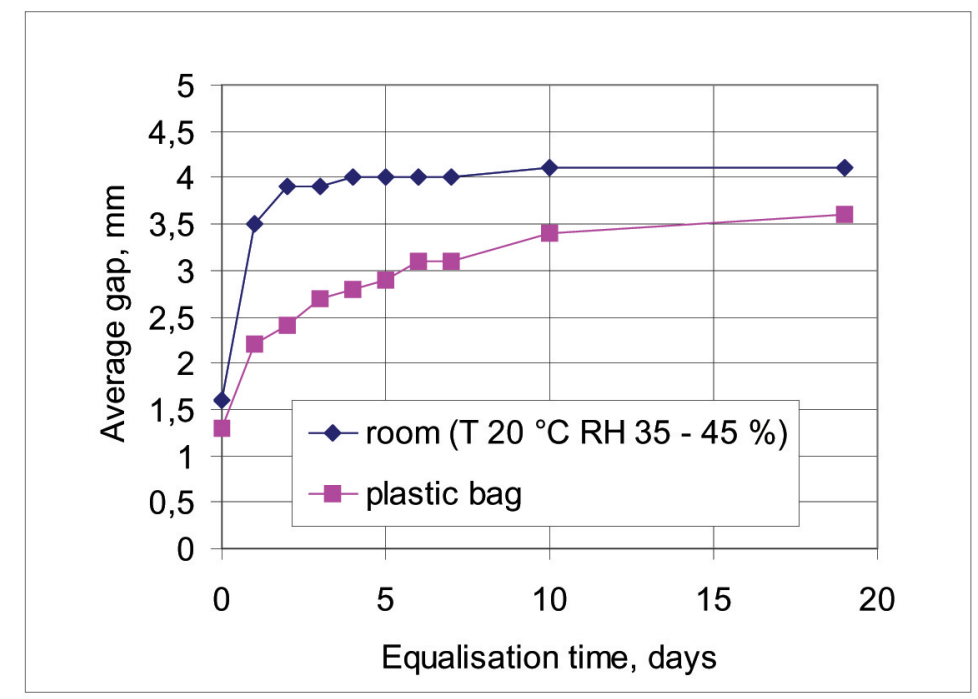

Figure 4. Cupping of sliced specimens in plastic bags and in room conditions. Spruce $32 \times 125 \mathrm{~mm}$ dried in a progressive kiln for 72 hours $\left(\mathrm{T}_{\mathrm{dry}}=64^{\circ} \mathrm{C}, \mathrm{T}_{\text {wet }}=52^{\circ} \mathrm{C}\right)$. The points are average values of 20 specimens.

\section{Measured and calculated CEN gap after different dryings and conditionings}

Table 9 presents the measured and PEO-model-calculated CEN gap after different dryings and conditionings. 
Table 9. Average moisture content as well as measured and calculated CEN gap after different dryings and conditionings. Timber thickness $50 \mathrm{~mm}$.

\begin{tabular}{|l|c|c|c|c|c|c|}
\hline Drying & Species & $\begin{array}{c}\text { MC } \\
\%\end{array}$ & $\begin{array}{c}\text { CEN gap (24h) } \\
\text { mm }\end{array}$ & $\begin{array}{c}\text { CEN gap (7d) } \\
\text { mm }\end{array}$ \\
\hline & & & meas. & PEO & meas. & PEO \\
\hline fast & Pine & 10,1 & 0,9 & 2,0 & 1,2 & 2,8 \\
\hline fast + steam cond * & Pine & 11,2 & $-0,1$ & 1,4 & 0,0 & 1,9 \\
\hline slow + cond in mill & Pine & 9,0 & 0,6 & 0,4 & 0,7 & 0,4 \\
\hline OTC & Pine & 9,1 & 0,6 & 1,1 & 0,8 & 1,2 \\
\hline OTC + steam cond * & Pine & 10,6 & 0,4 & 1,0 & 0,4 & 1,1 \\
\hline fast & Spruce & 10,6 & 1,4 & 1,5 & 1,8 & 1,7 \\
\hline fast + steam cond. * & Spruce & 11,8 & 0,2 & 0,7 & 0,4 & 1,0 \\
\hline slow & Spruce & 8,7 & & 1,0 & & 1,2 \\
\hline HTD & Spruce & 11,8 & 2,1 & - & 2,5 & - \\
\hline HTD + steam cond. * & \multicolumn{7}{|l|}{ Spruce } & 11,9 & 1,2 & - & 1,6 & - \\
\hline \multicolumn{7}{|l|}{$* 2.5$ steam conditioning after transport to VTT } \\
\end{tabular}

The results show that high-temperature drying without conditioning results in severe case hardening. Slow drying gives better values than fast drying, but with effective conditioning it is possible to remove the case hardening after fast drying.

There is no good correlation between measured and simulated case hardening values. Coefficient of determination is 0.14 for all values and 0.31 in cases without conditioning. One reason for this is that the parameters in the PEO model are not fully correct for the material dried in a particular sawmill. Another reason is that the real drying schedule of each test specimens is not known exactly. Despite of that PEO does show the tendencies how drying schedule affects on case hardening and it is so a useful tool for analysing drying schedules. PEO underestimates the effect of steam conditioning on the CEN gap. So it is necessary to define parameters separately for the situation of moisture intake.

Figures 5 and 6 show the experimental results of the effects of the conditioning climate and time on case hardening, moisture content and moisture gradient. Figure 5 presents the situation after fast drying and Figure 6 after fast drying and additional effective steam conditioning after cooling. The CEN gap was measured $24 \mathrm{~h}$ after the slicing as instructed in the standard and also after one and four weeks.

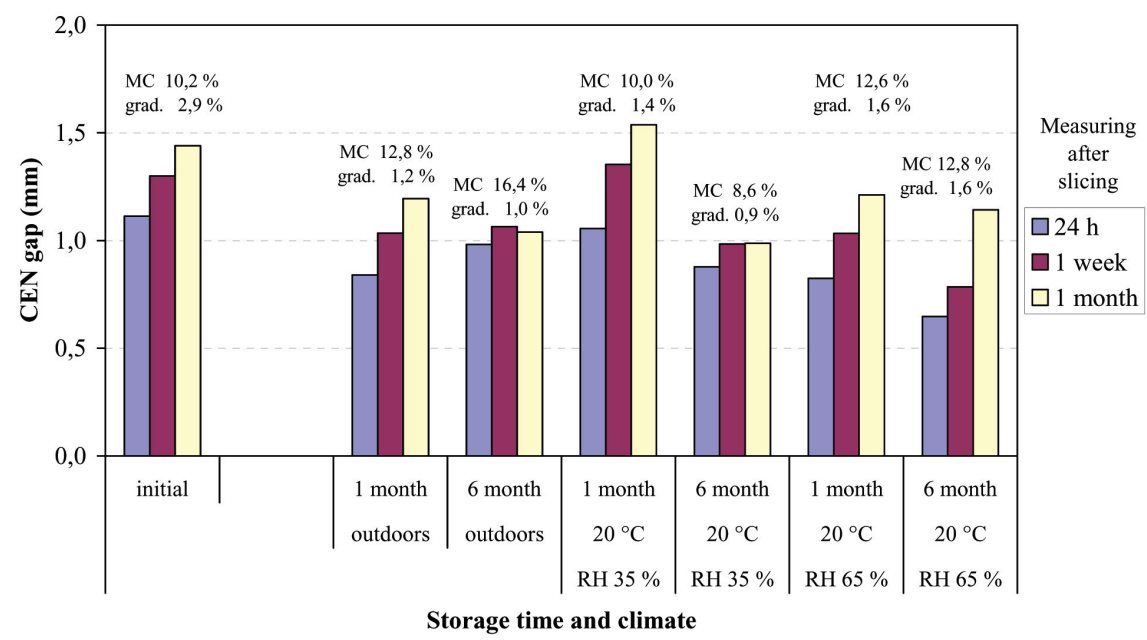

Figure 5. Case hardening, moisture content and moisture gradient after fast drying and after 1 and 6-month storage in different climates. Scots Pine $50 \times 140 \mathrm{~mm}^{2}$. CEN gap is measured $24 \mathrm{~h}, 1$ week and 1 month after the slicing. 


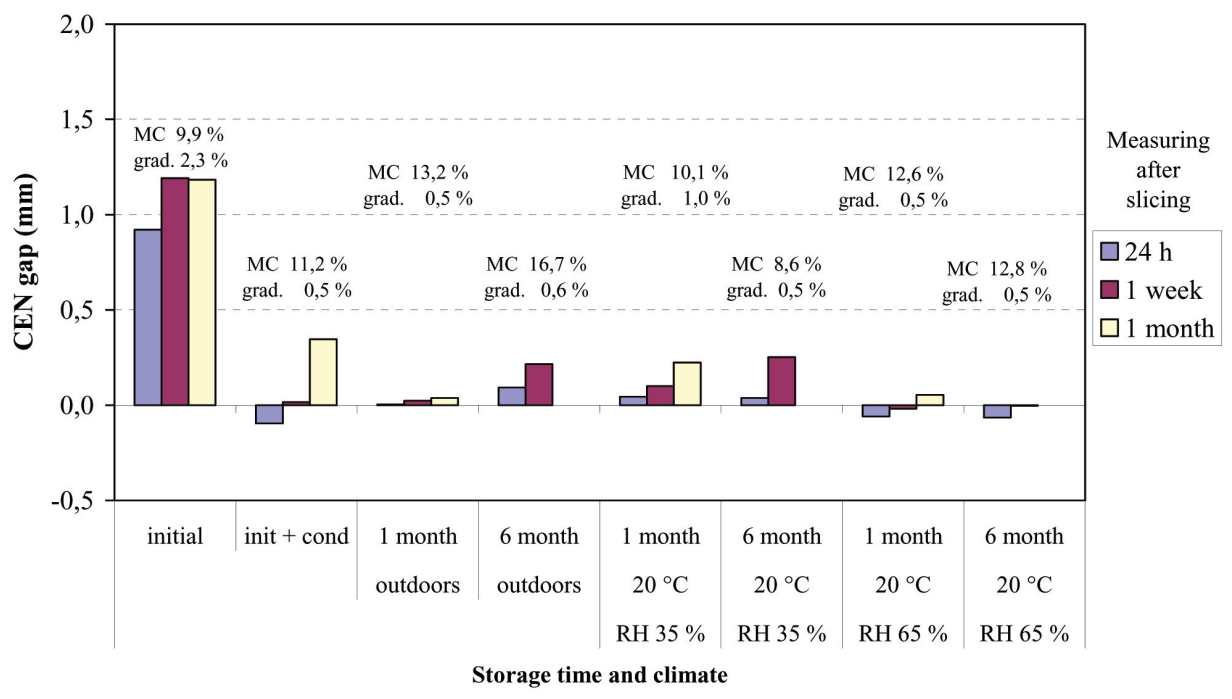

Figure 6. Case hardening, moisture content and moisture gradient after fast drying and steam conditioning, and after 1 and 6-month storage in different climates. Scots Pine $50 \times 140 \mathrm{~mm}^{2}$. CEN gap is measured $24 \mathrm{~h}, 1$ week and 1 month after the slicing.

It can be seen that it is possible to effectively remove case hardening with proper conditioning.

\section{CONCLUSIONS}

As a conclusion of the expert interviews, case hardening was defined as follows: Case hardening is a feature of dried wood that causes deformation (cupping) after re-sawing and equalizing of the moisture content.

Analyses with the finite element program PEO have shown that case hardening is not predicted by the moisture content gradient alone. The experimental results give the same conclusion. However, the case hardening gap after drying to a high final moisture content of $18 \%$ is nearly identical to the calculatory gap caused by cupping when the moisture gradients of the two halves of the test piece are equalized.

According to the simulations and experiments, the proposed time (24 hours) to keep the sliced specimens in a plastic bag before case hardening measurement is too short to show the total cupping. Thus the test doesn't show the whole cupping tendency of, for example, panels when the moisture content is equalized after re-sawing the studs and planing the billets. However, the $24 \mathrm{~h}$ value is about $70-80 \%$ of the value after 1 month, which is enough for a practical test to show the tendency.

The measurements and simulations show that case hardening increases with an increasing drying rate. With effective conditioning at drying temperature, or with steaming after cooling, it is easy to reduce or remove the case hardening. But at normal temperatures in use or storage of timber the case hardening diminishes very slowly, despite equalizing the moisture content in the cross-section.

Correlation between case hardening after industrial drying and simulated values was quite poor. The main reason for that are variations in timber properties and differences between average drying schedule in an industrial kiln and the drying climates just around the measured test specimens.

Despite of the differences of numerical values compared to test values the model may be used as a tool to analyze the tendencies to case hardening after different drying schedules. 


\section{REFERENCES}

CEN standard ENV 14464:2002 Sawn timber - Method for assessment of case-hardening

Hanhijärvi, A.; Mackenzie-Helnwein, P. 2003. Computational Analysis of Quality Reduction during Drying of Lumber due to Irrecoverable Deformation. I: Orthotropic Viscoelastic-Mechanosorptive-Plastic Material Model for the Transverse Plane of Wood. Journal of Engineering Mechanics 129(9):996-1005.

Hukka, A. 1996. A Simulation Program for Optimisation of Medium Temperature Drying on an Industrial Scale. 5th International IUFRO Wood Drying Conference, August 13-17, 1996, Quebec City, Canada. pp $41-48$.

Mackenzie-Helnwein, P.; Hanhijärvi, A. 2003. Computational Analysis of Quality Reduction during Drying of Lumber due to Irrecoverable Deformation. II: Algorithmic Aspects and Practical Application. Journal of Engineering Mechanics 129(9):1006-1016.

Ranta-Maunus, A. 1994. Computation of moisture transport and drying stresses by a 2-D FEprogramme. Proc. of 4th IUFRO Int. Conf. on Wood Drying, August 9-13, 1994, Rotorua NZ. New Zealand Forest Research Institute, Rotorua, NZ. pp. 187-194.

Ranta-Maunus, A.; Forsén, H.; Tarvainen, V. 2001. Analysis of Case Hardening. Proceedings of the 3rd Workshop of Cost Action E15 on Softwood Drying to Specific End-uses, 11 - 13 June 2001, Helsinki, Finland

APPENDIX 1 Case hardening test according the CEN standard ENV 14464:2002 Sawn timber Method for assessment of case-hardening

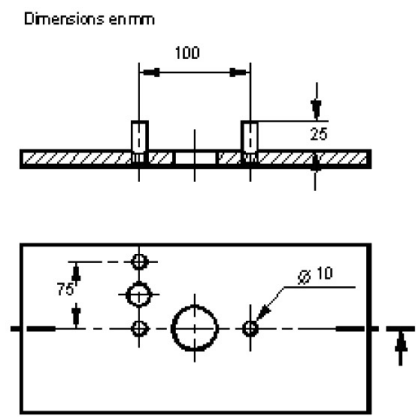

Figure 1: Test jig for assessment of casehardening

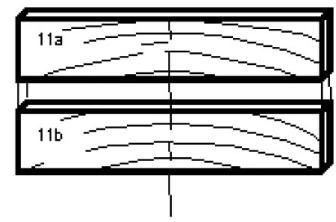

Figure 3: Separation and marking of test slice

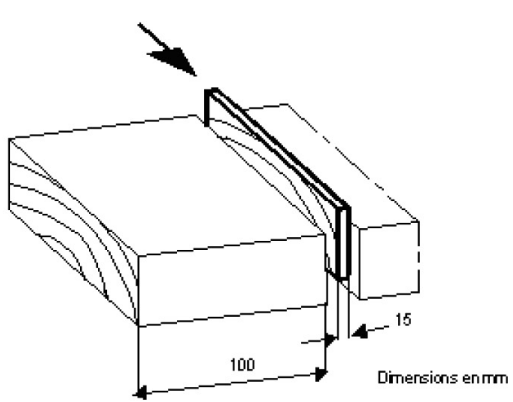

Figure 2: Preparation of test slice
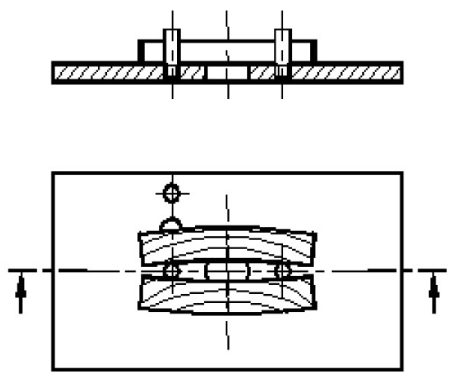

Figure 4 : Evaluation of casehardening with test jig 